\title{
Respiratory infections by Achromobacter xylosoxidans in a cohort of Cystic Fibrosis patients: identification, antimicrobial susceptibility and molecular epidemiology
}

\author{
Antonietta Lambiase', Maria Rosaria Catania', Mariassunta Del Pezzo', Valeria Raia², Antonino Giangrasso', \\ Fabio Rossano' \\ I Department of Cellular and Molecular Biology and Pathology “Luigi Califano”, \\ 2 Department of Pediatrics, Regional Cystic Fibrosis Center, University of Naples "Federico II", Italy
}

Key words: Achromobacter xylosoxidans, cystic fibrosis, epidemiology, antimicrobial susceptibility

Infezioni respiratorie da Achromobacter xylosoxidans in pazienti con Fibrosi Cistica: identificazione, suscettibilità agli antimicrobici ed epidemiologia molecolare

\section{SUMMARY}

Pulmonary infections by Gram-negative bacteria such as Achromobacter xylosoxidans are recovered frequently in patients with Cystic Fibrosis. Aims of this study were to value the isolation frequency of A.xylosoxidans strains in a cohort of Cystic Fibrosis patients, to investigate their antimicrobial sensitivity and to establish possible clonal likeness among strains. A retrospective study was undertaken between January 2004 and December 2008 on 300 patients receiving care at the Regional Cystic Fibrosis Centre of "Federico II" University, Naples.

Sputum samples were collected and selective media as well as commercial systems for bacterial identification were used. The activity of antimicrobial agents was determined using diffusion and micro-dilution methods. For DNA-fingerprinting, a genomic DNA macrorestriction followed by pulsed-field gel electrophoresis was carried out. A total of 238 strains from $5 \mathrm{I}$ patients were isolated. Strains were resistant to aztreonam, about half of these were resistant to gentamicin and trimethoprim-sulphamethoxazole. They were sensitive to piperacillin, piperacillin/tazobactam, and also to carbapenems, quinolones, cephalosporines. Macrorestriction analysis applied on some isolates showed substantial heterogeneity among strains. Actually, the prognostic role of A. xylosoxidans in Cystic Fibrosis is unclear, but this finding must imply difficulties on therapeutic approach. So, it is need to be on the look out regard such microorganisms. Preliminary results of DNA-fingerprinting indicate no evidence of clonal likeness and then of patient-to-patient spread.

Over the past 20 years, the epidemiology of bacteria involved in acute respiratory infections in Cystic Fibrosis has become increasingly complex. In recent years, the non-fermenting Gram-negative bacilli such as Stenotrophomonas maltophilia, A. xylosoxidans and Burkholderia cepacia complex have been identified as emerging pathogens (2-5, 7, 8, 10-13). In particular, Achromobacter xylosoxidans is a Gram-negative aerobic bacillus, oxidase-positive, non-lactose fermenting, widely distributed in the natural environment. It is an opportunistic human pathogen capable of causing a variety of infections, including bacteraemia, meningitis, pneumonia and peritonitis, particularly in immunocompromised hosts and patients with underlying diseases (10). It has been recently reported an increasing prevalence of $A$. xylosoxidans in patients with Cystic Fibrosis but few data about the clinical impact of this infection are reported (13).

Aims of this study were to value the isolation frequency of $A$. xylosoxidans strains in a cohort of Cystic Fibrosis patients, to investigate their antimicrobial sensitivity and to establish possible clonal likeness among strains.

\section{Study population}

A retrospective chart review of microbiological samples (sputum) obtained by 300 Cystic Fibrosis patients (mean age 16.21 years; range $0.5-50$ years) regularly attending Regional Referral Cystic Fibrosis Center of Naples was undertaken. Sputum samples were collected during the period January 2004-December 2008. Cystic Fibrosis was diagnosed on the basis of standard methods: sweat chloride test above 60 $\mathrm{mmol} / \mathrm{l}$ by pilocarpine and presence of two relevant Cystic Fibrosis transmembrane regulator (CFTR) mutations. Patients over 6 years of age had at least one lung function evaluation as measured by forced expiratory volume in $1 \mathrm{~s}$ $\left(\mathrm{FEV}_{1}\right)$ for each year of observation during clinical examinations and/or hospital discharge expressed as a percentage of predicted values for age, sex, ethnic background, weight and height.
For each patient, information about anthropometric parameters, pancreatic status, mean number of pulmonary exacerbations requiring intravenous antibiotic in the previous 12 months were obtained from our existing patient database.

Sputum samples for microbiological studies were obtained from each patient at least quarterly at clinical examinations. Patients infected by $A$. xylosoxidans were characterized for age, age of acquisition of first infection, co-infection, lung function and death. Chronic infection was defined as persistent presence of 3 positive cultures for at least 6 consecutive months, sporadic infection was defined as presence of less than 3 positive cultures for year, intermittent infection was defined as presence of 3 non consecutive positive cultures for year. According to the definition of the CDC, multidrug resistance was defined when a pathogen was resistant to one or more antibiotics (16).

Processing of sputum samples, bacterial culture and phenotypic analysis

Sputum samples were mixed with equal volumes of $1 \%$ dithiothreitol before incubation at $37^{\circ} \mathrm{C}$ for $30 \mathrm{~min}$. All specimens were examined microscopically and plated on several agar media, including MacConkey agar, Sabouraud agar, CNA agar at $37^{\circ} \mathrm{C}$ for $24-48 \mathrm{~h}$.

All isolates obtained from the samples were identified by the Phoenix system (Becton Dickinson); the API 20 NE identification system (bioMérieux) was used to confirm the identification of Gram-negative non-fermentative bacteria.

\section{Antimicrobial susceptibility testing method}

To assess the sensitivity of $A$. xylosoxidans strains to antimicrobial agents, an agar-diffusion method (Kirby-Bauer) and a broth microdilution assay using an automated system (Phoenix) were used. For this study, only most recent isolate of each patient was used for assay. Interpretative criteria for susceptibility for all the methods used in the study were in accordance with NCCLS criteria (11). The following drugs

\section{Corresponding author: Antonietta Lambiase}

PhDDepartment of Cellular and Molecular Biology and Pathology "Luigi Califano",

University of Naples "Federico II", Italy - Tel. -39-08I-7462530

E-mail:alambias@unina.it 
were assayed: amikacin, aztreonam, piperacillin, piperacillintazobactam, cefotaxime, cefepime, ceftazidime, ciprofloxacin, levofloxacin, chloramphenicol, imipenem, meropenem, trimethoprim-sulfamethoxazole, and gentamicin.

\section{Genotyping by PFGE}

DNA fingerprinting was carried out by the method of Grothues (5) and only most recent isolate of each patient was used for assay. In brief, isolates had grown overnight on nutrient agar and suspended in SE buffer $(75 \mathrm{mM} \mathrm{NaCl}, 25$ mM EDTA, pH 7.5). Cell suspensions (4 McFarland) were mixed with an equal volume of $1.8 \%$ low-melting point agarose, molded into plugs at $4^{\circ} \mathrm{C}$, and lysed with lysis buffer (1\% N-lauryl sarcosine, EDTA 0.5 M, ph 8.00) added with Proteinase K; the DNA inserts were digested with SpeI, according to the supplier's instruction (New England Biolabs).

Macrorestriction fragments were separated using CHEF III (Biorad) at $10^{\circ} \mathrm{C}$ for $20 \mathrm{~h}$, with start time of $5 \mathrm{~s}$ and end-pulse time of $35 \mathrm{~s}$, at a field strength of $6 \mathrm{~V} / \mathrm{cm}$. A concatemer ladder of lambda phage DNA was used as a size marker. Fragment patterns were compared according to the criteria of Tenover (18). Based on these criteria, we considered possibly related isolates if their restriction patterns differed by 4-6 bands and closely related if their restriction patterns differed by no more than 2-3 bands. Isolates were considered different if their restriction patterns differed by 7 or more bands. During the study period, we obtained 238 isolates of $A$. xylosoxidans from 51 patients (males 22; mean age 21 years; range 6-50 years); 6/51 (12\%) patients had chronic infection and were co-colonized by $P$. aeruginosa. Patients with intermittent infections were 6/51 (12\%).

On the basis of the definition applied in this study, 10 strains (19.6\%) were multidrug-resistant (MDR) showing resistance to aztreonam (MIC>16 $\mu \mathrm{g} / \mathrm{mL}$ ), cephalosporins, including cefepime (MIC>16 $\mu \mathrm{g} / \mathrm{mL}$ ), ceftazidime (MIC>16 $\mu \mathrm{g} / \mathrm{mL}$ ) and cefotaxime (MIC>32 $\mu \mathrm{g} / \mathrm{mL}$ ), carbapenem (imipenem MIC $>8 \mu \mathrm{g} / \mathrm{mL}$; meropenem MIC>8 $\mu \mathrm{g} / \mathrm{mL}$ ), aminoglycosides (amikacin MIC>32 $\mu \mathrm{g} / \mathrm{mL}$; gentamicin MIC $>8$ $\mu \mathrm{g} / \mathrm{mL}$ ), ciprofloxacin (MIC>2 $\mu \mathrm{g} / \mathrm{mL}$ ); levofloxacin (MIC $>4 \mu \mathrm{g} / \mathrm{mL}$ ), trimethoprim-sulfamethoxazole (MIC>2/38 $\mu \mathrm{g} / \mathrm{mL}$ ). All strains were sensitive to piperacillin (MIC $<4$ $\mu \mathrm{g} / \mathrm{mL}$ ) and piperacillin/tazobactam (MIC $<4 / 4 \mu \mathrm{g} / \mathrm{mL}$ ). Table 1 shows results of antimicrobial susceptibility testing. PFGE analysis, applied on 14/51 isolates, showed a high heterogeneity of restriction patterns.

Table I. Number of isolates with resistant (R), intermediate (I) and sensible (S) values to antimicrobial agents

\begin{tabular}{llll}
\hline Antimicrobial agent & R & I & S \\
\hline Amikacin & $I 5$ & 5 & 3 I \\
\hline Aztreonam & 5 I & - & - \\
\hline Cefepime & 14 & 8 & 29 \\
\hline Cefotaxime & 14 & 8 & 29 \\
\hline Ceftazidime & 10 & 2 & 39 \\
\hline Ciprofloxacin & 10 & 5 & 36 \\
\hline Chloramphenicol & - & 12 & 39 \\
\hline Gentamicin & 20 & 7 & 24 \\
\hline Imipenem & 10 & 1 & 39 \\
\hline Levofloxacin & 10 & 5 & 36 \\
\hline Meropenem & 10 & 1 & 40 \\
\hline Piperacillin & - & - & 5 I \\
\hline Piperacillin-tazobatactam & - & - & 5 I \\
\hline Trimethoprim-sulfamethoxazole & 20 & I & 30 \\
\hline
\end{tabular}

Bacterial biodiversity in Cystic Fibrosis lung is quite widespread (15, 6-9); in a study of 2002, Coenye and coworkers reported the presence of very unusual bacteria such as Acinetobacter spp, Bordetella spp, Moraxella spp, Comamonas spp, Rhizobium spp, Herbaspirillum spp. and Inquilinus limosus in sputum samples of Cystic Fibrosis patients (2). Consequently, each bacterial isolate must be correctly identified because the bacterial misidentification represents a challenge to infection control, antimicrobial therapy and patient prognosis. Saiman et al, in a report of 2001 (14), reported evidence of some weakness of commercial systems for phenotypic identification of non-fermentative Gram-negative bacteria recovered from Cystic Fibrosis patients. In the present study, biochemical identification by API $20 \mathrm{NE}$ proved to be useful strategy for distinguishing A. xylosoxidans from other bacteria.

In our cohort of patients, $12 \%$ of these were considered chronically infected by $A$. xylosoxidans and same percentage was found for patients with intermittent infections. The percentage of chronically infections is more high if compared with other data, as those referred by Tan and coworker (17), or by Burns and coworkers (1).

As Cystic Fibrosis patients are living longer thanks to more intense treatment, multidrug-resistant bacteria are being increasingly isolated from respiratory tract. Bacterial resistance to antibiotics is enhanced by antimicrobial selection pressure. Owing to multiple mechanisms of antimicrobial resistance, these microorganisms are difficult to treat and often require antibiotic associations. On the basis of definition applied in this study for identification of MDR bacteria, we found 10/51 isolates resistant at least to one antimicrobial agent. Profiles of antimicrobial susceptibility of our isolates are in accordance with data reported by other works (14).

We found clonal heterogeneity of bacteria at least among 14 infected patients, as demonstrated by PFGE patterns, but continual epidemiological survey is necessary.

In conclusion the identification systems used in this study are suitable for the accurate identification of $A$. xylosoxidans from Cystic Fibrosis patients and our preliminary results are indicative of high heterogeneity among strains; furthermore, we confirmed the multi-drug resistance of these microorganisms. Our data indicate that careful bacterial isolation and DNAfingerprinting are critical for predicting the spread of strains, improving therapeutic measures and increasing our understanding of the epidemiology of these pathogens.

\section{BIBLIOGRAPHY}

1. Burns Jl, Emerson J, Stapp JR, et al. Microbiology of sputum from patients at Cystic Fibrosis centers in the United States. Clin Infect Dis 1998; 27 (1): 158-63.

2. Coenye T, Goris J, Spilker T, Vandamme P, Lipuma JJ. Characterization of unusual bacteria isolated from respiratory secretions of Cystic Fibrosis patients and description of Inquilinus limosus gen. nov., sp. nov. J Clin Microbiol 2002; 40: 2062-9.

3. Frederiksen B, Koch C, Høiby N. Changing epidemiology of Pseudomonas aeruginosa infection in Danish Cystic Fibrosis patients (1974-1995). Pediatr Pulmunol 1999; 28 (3): 159-66.

4. Gilligan PH, Whittier S. Burkholderia, Stenotrophomonas, Ralstonia, Brevundimonas, Comamonas, and Acidovorax, p. 526-538. In Murray PR, Baron EJ, Pfaller MA, Tenover FC, Yolken RH (ed.), Manual of clinical microbiology, $7^{\text {th }}$ ed. American Society for Microbiology, 1999, Washington, D.C.

5. Grothues D, Koopmann U, Van der Hardt H, Tummler B. Genome fingerprinting of Pseudomonas aeruginosa indicates colonization of Cystic Fibrosis siblings with closely related strains. J Clin Microbiol 1988; 26: 115-23.

6. Lambiase A, Del Pezzo M, Raia V, Sepe A, Ferri P, Rossano F. Chryseobacterium respiratory tract infections in patients with Cystic Fibrosis. J Infect 2007; 55: 518-23.

7. Lambiase A, Raia V, Del Pezzo M, Sepe A, Carnevale V, Rossano F. Microbiology airway disease in a cohort of patients with Cystic Fibrosis. BMC Inf Dis 2006; 6 (1): 4.

8. Lambiase A, Raia V, Stefani S, et al. Burkholderia cepacia complex infection in a cohort of Italian patients with Cystic Fibrosis J Microbiol 2007; 45 (3): 275-9.

9. Lambiase A, Rossano F, Del Pezzo M, et al. Sphyngobacterium respiratory tract infection in patients with Cystic Fibrosis. BMC Res Notes 2009; 23: 262.

10. Liu L, Coenye T, Burns JL, PW Whitby, Stull TL, Li Puma JJ. Ribosomal DNA-direct PCR for identification of Achromobacter (Alcaligenes) xylosoxidans recovered from sputum samples from Cystic Fibrosis patients. J Clin Microbiol 2002; 40: 1210-3.

11. National Committee for Clinical Laboratory Standards. Methods for dilution antimicrobial susceptibility tests for bacteria that grow aerobically, 5th edn. Approved standard M7-A5. National Committee for Clinical Laboratory Standards, 2002, Wayne, PA 
12. Ramsey BW. Management of pulmonary disease in patients with cystic fibrosis. $N$ Engl J Med 1996; 335: 179-88.

13. Raso T, Bianco O, Grosso B, Zucca M, Savoia D. Achromobacter xylosoxidans respiratory tract infections in cystic fibrosis patiernts. APMIS 2008 118: 837-41.

14. Saiman L, Chen Y, Tabibi S, et al. Identification and antimicrobial susceptibility of Alcaligenes xylosoxidans isolated from patients with Cystic Fibrosis. J Clin Microbiol 2001; 39: 3942-5.

15. Saiman L, MacDonald NE, Whittier S. The microbiological basis for antimicrobial therapy. In Tenth Annual North American Cystic Fibrosis Conference. 1996: Cystic Fibrosis Foundation

16. Siegel JD, Rhinehart E, Jackson M, Chiarello L. Management of mul- tidrug-resistant organisms in healthcare settings: the Healthcare Infection Control Practices Advisory Committee. Centers for Disease Control and Prevention 2006;1-74.

17. Tan K, Conway SP, Brownlee KG, Etherington C, Peckham DG. Alcaligenes infection in cystic fibrosis. Pediatr Pulmonol 2002; 34: 101-4.

18. Tenover F, Arbeit R, Goering R, et al. Interpreting chromosomal DNA restriction patterns produced by pulsed-field gel electrophoresis: criteria for bacterial strain typing. J Clin Microbiol 1995; 33: 2233-9.

19. Vu-Thien H, Moissenet D, Valcin M, Dulot C, Tournier G, Garbarg-Chenon A. Molecular epidemiology of Burkholderia cepacia, Stenotrophomonas maltophilia, and Alcaligenes xylosoxidans in a cystic fibrosis centre. Eur J Clin Microbiol Infect Dis 1996; 15: 249-60. 